\title{
MODELLING AND OPTIMIZATION OF TRANSESTERIFICATION OF PALM KERNEL OIL CATALYSED BY CALCIUM OXIDE DERIVED FROM HEN EGGSHELL WASTES
}

\author{
Akhabue, C. E.* and Ogogo, J. A. \\ Department of Chemical Engineering, Faculty of Engineering, \\ University of Benin, Benin City, Nigeria \\ *Corresponding Author: christopher.akhabue@uniben.edu \\ (Received: $27^{\text {th }}$ November, 2017; Accepted: $4^{\text {th }}$ February, 2018)
}

\section{ABSTRACT}

\begin{abstract}
In this study, modelling and optimization of transesterification of palm kernel oil (PKO) catalysed by calcium oxide $(\mathrm{CaO})$ derived from hen eggshell wastes were investigated. The eggshells were calcined for $5 \mathrm{~h}$ at $900{ }^{\circ} \mathrm{C}$. The catalyst derived from the eggshells after calcination was characterized by Fourier transform infrared (FTIR), scanning electron microscope (SEM) and $\mathrm{X}$ - ray fluorescence (XRF). The XRF results shows that the catalyst contains $98.16 \%$ of $\mathrm{CaO}$. Variables for the transesterification of the $\mathrm{PKO}$ were optimized using response surface methodology (RSM) based on central composite design (CCD). The variables investigated were methanol to oil molar ratio, catalyst concentration, reaction temperature and time. A second order quadratic model ( $\mathrm{p}<0.0001)$ was developed for predicting the biodiesel yield. The model predicted maximum biodiesel yield of $96.395 \%$ under the following optimum process conditions: methanol to oil molar ratio of 9.02:1, catalyst concentration of $3.106 \mathrm{wt} . \%$, temperature of $51.4^{\circ} \mathrm{C}$ and reaction time of $135.94 \mathrm{~min}$. The value of the biodiesel yield predicted was close to the experimental value of $94.63 \%$. Physicochemical properties of the biodiesel obtained were within the American Society for Testing and Materials (ASTM) standards for biodiesel. Hence, heterogeneous catalyst derived from eggshells wastes can be used for transesterification.
\end{abstract}

Keywords: Eggshells, Calcium Oxide, Transesterification, Optimization, PKO

\section{INTRODUCTION}

Biodiesel, a promising alternative fuel to petroleum-based diesel fuel used in compression ignition (CI) engines has become the focus of many researchers in recent times. Biodiesel is produced by reacting vegetable oils or animal fats with a low molecular weight alcohol, preferably methanol and ethanol in the presence of a catalyst. This reaction is known as transesterification. The use of biodiesel fuel instead of petroleum-based fuel in CI engines has several advantages. These include, its high flash point, non-toxic nature and above all, it is biodegradable and also renewable. Less emission of $\mathrm{CO}_{2}$ and oxides of nitrogen and sulphur are also advantages of using biodiesel in CI engines (Monyem and Van Gerpen, 2001; Hess et al., 2007). Homogeneous catalysts such sodium hydroxide $(\mathrm{NaOH})$ and potassium hydroxide $(\mathrm{KOH})$ have been used in transesterification reactions (Shahla et al. 2012; Dharma et al., 2016; Akhabue and Okwundu, 2017). Although, these homogeneous catalysts exhibit high catalytic activity, several problems have been identified with their uses (Tariq et al., 2012). Some of these problems include the followings: low biodiesel yield due to the formation of emulsion, the catalyst is not reusable and more water is used during the washing process. The waste water from the washing process also requires further treatment which leads to additional costs. As a result, many researchers have focused attention on the use of heterogeneous catalysts for biodiesel production due to its convenience in separation and reusability (Birla et al., 2012; Viriya-empikul et al., 2012; Rezaei et al., 2013; Zeng et al., 2015; Eswararao et al., 2016; Gupta and Agarwal, 2016; Ye et al., 2016; Kostic et al., 2016). The heterogeneous catalysed systems consist of three phases (oil/methanol/catalyst). On adsorption of methanol on the catalyst surface, the active methoxide specie is formed. The rate at which the methoxide is formed is related to the efficiency of the catalyst.

Several waste materials have been utilised as heterogeneous catalyst for the production of biodiesel. Birla et al. (2012) used snail shell as catalyst in the synthesis of biodiesel from waste frying oil and obtained a biodiesel yield of $87.28 \%$ under optimum conditions of 6.02:1 methanol to oil ratio, 2 wt. $\%$ catalyst concentration and temperature of $60^{\circ} \mathrm{C}$ after $8 \mathrm{~h}$ of reaction. Viriya- 
empikul et al. (2012) in another study used Cabased solid catalyst derived from industrial wastes for the production of biodiesel from palm olein oils. Heterogeneous mussel shell was used as catalyst for the production of biodiesel from soybean oil by Rezaei et al. (2013). A maximum biodiesel yield of $94.1 \%$ was obtained at a catalyst concentration of $12 \mathrm{wt} . \%$, methanol to oil ratio of 24.1:1 and at a temperature of $60^{\circ} \mathrm{C}$ after $8 \mathrm{~h}$.

In a recent study conducted by Eswararao et al. (2016), a mixture of natural shells was used as solid catalyst in the transesterification of Jatropha oil. Gupta and Agarwal (2016) used snail shell modified with $\mathrm{KOH}$ as catalyst for the production of biodiesel from soybean oil. A biodiesel yield of 96\% was obtained. Kostic et al. (2016) used palm kernel shell biochar as heterogeneous catalyst for the transesterification of sunflower oil.

In the present study, eggshell waste was used as heterogeneous catalyst for the transesterification of palm kernel oil (PKO). The catalyst derived from the eggshell was characterized by scanning electron microscope (SEM), Fourier transform infrared (FTIR) spectrophotometer and X - ray fluorescence (XRF). Transesterification was optimized by response surface methodology (RSM) with the aid of central composite design (CCD). The effect of methanol to oil molar ratio, catalyst concentration, temperature and time on the yield of biodiesel was investigated.

\section{MATERIALS AND METHODS}

\section{Materials}

Waste egg shells were collected from various eatery centres at the University of Benin, Benin City, Nigeria. Palm kernel oil (PKO) was supplied by Joe Chemicals in Onitsha, Anambra State in Nigeria. The physicochemical properties of the PKO are shown in table 1 . The chemicals used were methanol (99.5\%), ethanol (99.5\%), sulphuric acid, potassium hydroxide pellets and benzene $(99.5 \%)$. The chemicals were of analytical grade and supplied by Pyrex - IG Scientific Company, Benin City, Nigeria.

Table 1. Physico-chemical Properties of Palm Kernel Oil

\begin{tabular}{ll}
\hline Property (Unit) & Value \\
\hline Density at $27^{\circ} \mathrm{C}\left(\mathrm{kg} / \mathrm{m}^{3}\right)$ & 920 \\
Viscosity at $27^{\circ} \mathrm{C}\left(\mathrm{mm}^{2} / \mathrm{s}\right)$ & 9.8 \\
Iodine Value $(\mathrm{mg} \mathrm{KOH} / \mathrm{g}$ oil) & 81.25 \\
Acid Value $(\mathrm{mg} \mathrm{KOH} / \mathrm{g}$ oil) & 18.142 \\
FFA Content $(\%)$ & 9.061 \\
Saponification Value (mg KOH/g oil) & 203.7 \\
Water content $(\%)$ & 0.86 \\
Fatty acid composition & $($ mass \%) \\
Octanoic acid C8:0 & 1.618 \\
n-Decanoic acid C10:0 & 7.407 \\
Dodecanoic acid C12:0 & 50.454 \\
Tetradecanoic acid C14:0 & 17.865 \\
n-Hexadecanoic acid C16:0 & 9.878 \\
Oleic acid C18:1 & 12.778 \\
\hline
\end{tabular}

Preparation of Catalyst from the Waste Eggshells

The waste eggshells were washed with tap water to remove impurities from their surfaces. The washed eggshells were thereafter sun dried for three days. The dried eggshells were crushed to fine powder particles using a wooden mortar and pestle. Calcination of the particles was carried out using a muffle furnace for $5 \mathrm{~h}$ and the temperature was set to $900{ }^{\circ} \mathrm{C}$. The hot calcined samples were removed from the muffle furnace before the temperature of the furnace could reach room temperature and immediately placed inside a 
desiccator to cool. The samples were removed from the desiccator and kept in an air tight container to prevent reaction with moisture.

\section{Characterization of the Catalyst obtained from the Eggshells}

The chemical composition of the catalyst was analysed using an $\mathrm{X}$ - ray fluorescence spectrometer (PANalytical MiniPal 4) with an inbuilt XRD. The surface morphology of the catalyst derived from egg shells was observed by a scanning electron microscope (SEM). The SEM images were observed using Phenom ProX working at an accelerated voltage of $10 \mathrm{kV}$ and beam size of 3 . Micrographs were observed at 200 and $400 \mu \mathrm{m}$. The functional groups present in the catalyst were analysed using a Fourier transform infrared (FTIR) spectrophotometer (FTIR-8400 S, SHIMADZU) within the wavelength region of 750 to $4000 \mathrm{~cm}^{-1}$.

\section{Biodiesel Preparation \\ Pretreatment of the Palm Kernel Oil}

As shown in table 1, the free fatty acid (FFA) content of the PKO was more than $1 \%$, pretreatment of the $\mathrm{PKO}$ was therefore carried out to reduce the FFA content to less than 1\%. The pretreatment process of the oil also called esterification was carried out in a $1 \mathrm{~L}$ round bottom flask using a methanol to oil molar ratio of $7: 1$, sulphuric acid concentration of $1 \mathrm{wt} \%$ and at temperature of $60^{\circ} \mathrm{C}$. The reaction was carried out using a temperature controlled magnetic stirrer (Model No. HJ - 3D) for $2 \mathrm{~h}$. At the end of the reaction, the oily part was separated from the excess methanol and water. The FFA content of the treated oil was found to be less than $1 \%$.

\section{Transesterification Reaction}

Transesterification of the treated PKO was carried out in a $250 \mathrm{ml}$ conical flask using the temperature controlled magnetic stirrer. Briefly,
$50 \mathrm{~g}$ of the treated PKO was measured into the conical flask which was placed on the stirrer and heated to the desired temperature. A known weight of the catalyst was added to methanol and the mixture was thoroughly agitated. The catalystmethanol mixture was added to the heated PKO as soon as the desired temperature for reaction was reached. The magnetic stirrer was turned on and reaction was allowed to proceed. At the end of the reaction, the mixture was separated from the catalyst by decantation and filtration. The mixture was later transferred to a separating funnel and allowed to settle overnight. The glycerol bottom layer was separated from the biodiesel layer. The biodiesel was purified by washing with warm water. The process of washing involves adding warm water approximately one-third the volume of the biodiesel to the biodiesel inside the separating funnel. The washing process was carried out thrice. The washed biodiesel was later heated in an oven at a temperature of $80{ }^{\circ} \mathrm{C}$ in order to remove water that might still be present in the biodiesel. The biodiesel yield was obtained using Eq. (1).

Biodiesel yield $(\%)=\frac{\text { Mass of biodiesel }(\mathrm{g})}{50 \mathrm{~g} \text { of treated PKO }} \times 100$

\section{Experimental Design and Statistical} AnalysisCentral composite design (CCD) with four parameters was used to study the response pattern and to determine the optimum combination of variables. The effect of methanol to oil molar ratio $\left(\mathrm{X}_{1}\right)$, catalyst concentration $\left(\mathrm{X}_{2}\right)$, temperature $\left(\mathrm{X}_{3}\right)$ and time $\left(\mathrm{X}_{4}\right)$ at five variables levels in the transesterification process is presented in table 2 . The coded and actual levels of the variables used for the transesterification of the PKO are also presented in table 2. The variables were coded according to Eq. (2).

$X_{i}=\frac{x_{i}-x_{0}}{\Delta x}$ 
Table 2. Coded and actual levels for the four parameters in the CCD

\begin{tabular}{llllllll}
\hline SymbolFactor & \multicolumn{3}{c}{ Unit } & \multicolumn{7}{c}{ Levels } \\
\cline { 4 - 8 } & & & & & \\
\cline { 4 - 8 } & & & & & & \\
\hline $\mathrm{X}_{1}$ & Methanol:oil & $\mathrm{mol} / \mathrm{mol}$ & $(-1)$ & $(0)$ & $(1)$ & $(+2)$ \\
$\mathrm{X}_{2}$ & Catalyst conc. & wt.\% of oil & 1.0 & 9.0 & 12.0 & 15.0 & 18.0 \\
$\mathrm{X}_{3}$ & Temperature & ${ }^{\circ} \mathrm{C}$ & 40.0 & 46.3 & 52.5 & 58.8 & 65.0 \\
$\mathrm{X}_{3}$ & Time & min & 30.0 & 82.5 & 135.0 & 187.5 & 240.0 \\
\hline
\end{tabular}

where $X_{i}$ and $x_{i}$ are the actual and coded factors respectively, $\chi_{0}$ is the value $x_{i}$ at the centre point and $\Delta x$ is the step change. A total of 30 experimental runs were carried out in a random order to minimise the effects of explained variability in the observed responses due to extraneous factors. The experiments were carried out in duplicate and the mean biodiesel yield obtained are shown in table 3. Design - Expert $^{\circledR}$ software version 10 (Stat-Ease Inc., Minneapolis) was used for the regression and the plotting of the response surface plots.

The experimental data obtained from the transesterification reaction was analysed by the response surface regression using the polynomial equation shown in Eq. (3).

Table 3. Central Composite Design Matrix for Biodiesel yield

\begin{tabular}{|c|c|c|c|c|c|c|c|c|c|c|}
\hline \multirow{2}{*}{$\begin{array}{l}\text { Run } \\
\text { no. }\end{array}$} & \multicolumn{3}{|c|}{ Coded values } & \multicolumn{5}{|c|}{ Actual values } & \multicolumn{2}{|c|}{ Biodiesel yield (\%) } \\
\hline & $\mathrm{X}_{1}$ & $\mathrm{X}_{2}$ & $\mathrm{X}_{3}$ & $\mathrm{X}_{4}$ & $\mathrm{X}_{1}$ & $\mathrm{X}_{2}$ & $\mathrm{X}_{3}$ & $\mathrm{X}_{4}$ & Experiment. & Predicted \\
\hline 1 & 0.0 & 0.0 & 0.0 & 0.0 & 12 & 5 & 52.5 & 135 & 72.30 & 73.08 \\
\hline 2 & 0.0 & -2.0 & 0.0 & 0.0 & 12 & 1 & 52.5 & 135 & 88.59 & 85.84 \\
\hline 3 & 0.0 & 0.0 & 0.0 & 0.0 & 12 & 5 & 52.5 & 135 & 76.54 & 73.08 \\
\hline 4 & 1.0 & -1.0 & -1.0 & 1.0 & 15 & 3 & 46.3 & 187.5 & 61.08 & 62.38 \\
\hline 5 & 0.0 & 0.0 & 0.0 & 0.0 & 12 & 5 & 52.5 & 135 & 74.21 & 73.08 \\
\hline 6 & -1.0 & -1.0 & 1.0 & 1.0 & 9 & 3 & 58.8 & 187.5 & 70.28 & 69.11 \\
\hline 7 & 1.0 & 1.0 & 1.0 & -1.0 & 15 & 7 & 58.8 & 82.5 & 46.86 & 48.04 \\
\hline 8 & 2.0 & 0.0 & 0.0 & 0.0 & 18 & 5 & 52.5 & 135 & 56.32 & 54.00 \\
\hline 9 & 0.0 & 0.0 & 0.0 & 2.0 & 12 & 5 & 52.5 & 240 & 88.11 & 87.44 \\
\hline 10 & -1.0 & -1.0 & 1.0 & 1.0 & 9 & 3 & 58.8 & 82.5 & 78.92 & 79.99 \\
\hline 11 & 1.0 & 1.0 & -1.0 & 1.0 & 15 & 7 & 46.3 & 187.5 & 67.34 & 69.22 \\
\hline 12 & 0.0 & 0.0 & 0.0 & 0.0 & 12 & 5 & 52.5 & 135 & 70.00 & 73.08 \\
\hline 13 & 1.0 & 1.0 & 1.0 & 1.0 & 15 & 7 & 58.8 & 187.5 & 70.85 & 69.14 \\
\hline 14 & 0.0 & 0.0 & -2.0 & 0.0 & 12 & 5 & 40 & 135 & 16.26 & 13.90 \\
\hline 15 & -1.0 & 1.0 & 1.0 & -1.0 & 9 & 7 & 58.8 & 82.5 & 59.88 & 57.82 \\
\hline 16 & -1.0 & 1.0 & 1.0 & 1.0 & 9 & 7 & 58.8 & 187.5 & 36.34 & 38.22 \\
\hline 17 & -1.0 & 1.0 & -1.0 & 1.0 & 9 & 7 & 46.3 & 187.5 & 69.19 & 67.26 \\
\hline 18 & 1.0 & 1.0 & -1.0 & -1.0 & 15 & 7 & 46.3 & 82.5 & 26.65 & 27.07 \\
\hline 19 & -1.0 & -1.0 & -1.0 & 1.0 & 9 & 3 & 46.3 & 187.5 & 91.03 & 92.80 \\
\hline 20 & -2.0 & 0.0 & 0.0 & 0.0 & 6 & 5 & 52.5 & 135 & 94.07 & 94.19 \\
\hline 21 & 1.0 & -1.0 & -1.0 & -1.0 & 15 & 3 & 46.3 & 82.5 & 10.43 & 11.51 \\
\hline 22 & 0.0 & 0.0 & 0.0 & 0.0 & 12 & 5 & 52.5 & 135 & 73.51 & 73.08 \\
\hline 23 & -1.0 & 1.0 & -1.0 & -1.0 & 9 & 7 & 46.3 & 82.5 & 64.36 & 65.80 \\
\hline 24 & 1.0 & -1.0 & 1.0 & 1.0 & 15 & 3 & 58.8 & 187.5 & 66.13 & 67.65 \\
\hline 25 & 0.0 & 0.0 & 0.0 & 0.0 & 12 & 5 & 52.5 & 135 & 71.89 & 73.08 \\
\hline 26 & 0.0 & 2.0 & 0.0 & 0.0 & 12 & 9 & 52.5 & 135 & 69.95 & 70.51 \\
\hline 27 & 0.0 & 0.0 & 0.0 & -2.0 & 12 & 5 & 52.5 & 30 & 57.69 & 56.16 \\
\hline 28 & 0.0 & 0.0 & 2.0 & 0.0 & 12 & 5 & 65 & 135 & 11.02 & 11.18 \\
\hline 29 & -1.0 & -1.0 & -1.0 & -1.0 & 9 & 3 & 46.3 & 82.5 & 81.67 & 82.62 \\
\hline 30 & 1.0 & -1.0 & 1.0 & -1.0 & 15 & 3 & 58.8 & 82.5 & 36.66 & 37.83 \\
\hline
\end{tabular}




$$
\begin{aligned}
Y=b_{o}+\sum_{i=1}^{k} b_{i} X_{i} & +\sum_{i=1}^{k} b_{i i} X_{i}^{2} \\
& +\sum_{i>j}^{k} \sum_{j}^{k} b_{i j} X_{i} X_{j}+e
\end{aligned}
$$

where $\mathrm{Y}$ is the response tactor (b1odiesel yield), $\mathrm{X}_{\mathrm{i}}$ is the independent variables, $\mathrm{b}_{\mathrm{o}}$ is the intercept, $b_{i}$ is first order coefficient of the model $b_{i i}$ is the quadratic coefficient of the $i$ th factor, $b_{i j}$ is the linear coefficient of the model for the interaction between the $i$ th and $j$ th variables, $k$ is the number of variables and e is the experimental error.

The statistical significance of the model was checked using the analysis of variance (ANOVA) and the coefficient of determination $\left(R^{2}\right)$. The ANOVA was also used to determine the significance of each term in the model. The model was considered satisfactory when the ANOVA data showed a high level of significance.

Physicochemical Characterization of the Biodiesel

The physicochemical properties of the biodiesel obtained at the optimal process conditions were characterized according to the American Society for Testing and Materials (ASTM) D6751 standards. Basic fuel properties such as flash point, acid value, density, viscosity amongst others were carried out.

\section{RESULTS AND DISCUSSION \\ Characterization of the Catalyst}

The chemical composition of the catalyst derived from the eggshell is shown in table 4 . The catalyst contained a very high composition of calcium oxide $(98.16 \%)$ followed by $\mathrm{MnO}$ and $\mathrm{Fe}_{2} \mathrm{O}_{3}$. Some elements such as $\mathrm{Cr}, \mathrm{Sr}$, and $\mathrm{Cu}$ were also detected in trace amounts. The high composition of $\mathrm{CaO}$ in the calcined eggshell is a result of the fact that during calcination at high temperature, calcium carbonate present in eggshell (Laca et al., 2017 ) is decomposed to form $\mathrm{CaO}$ and $\mathrm{CO}_{2}$ according to reaction equation shown in Eq. (4).

$$
\mathrm{CaCO}_{3} \rightarrow \mathrm{CaO}+\mathrm{CO}_{2} \text { (gas) }
$$

The morphology of the catalyst derived from the eggshell were examined by observing the SEM images of the calcined eggshells at different magnifications as shown in Figure 1.

Table 4. Chemical composition of catalyst derived from eggshell

\begin{tabular}{lc}
\hline Oxides & Composition (\%) \\
\hline $\mathrm{CaO}$ & 98.16 \\
$\mathrm{Fe}_{2} \mathrm{O}_{3}$ & 0.64 \\
$\mathrm{MnO}$ & 0.206 \\
$\mathrm{TiO}_{2}$ & 0.089 \\
Trace elements & 0.905 \\
\hline
\end{tabular}

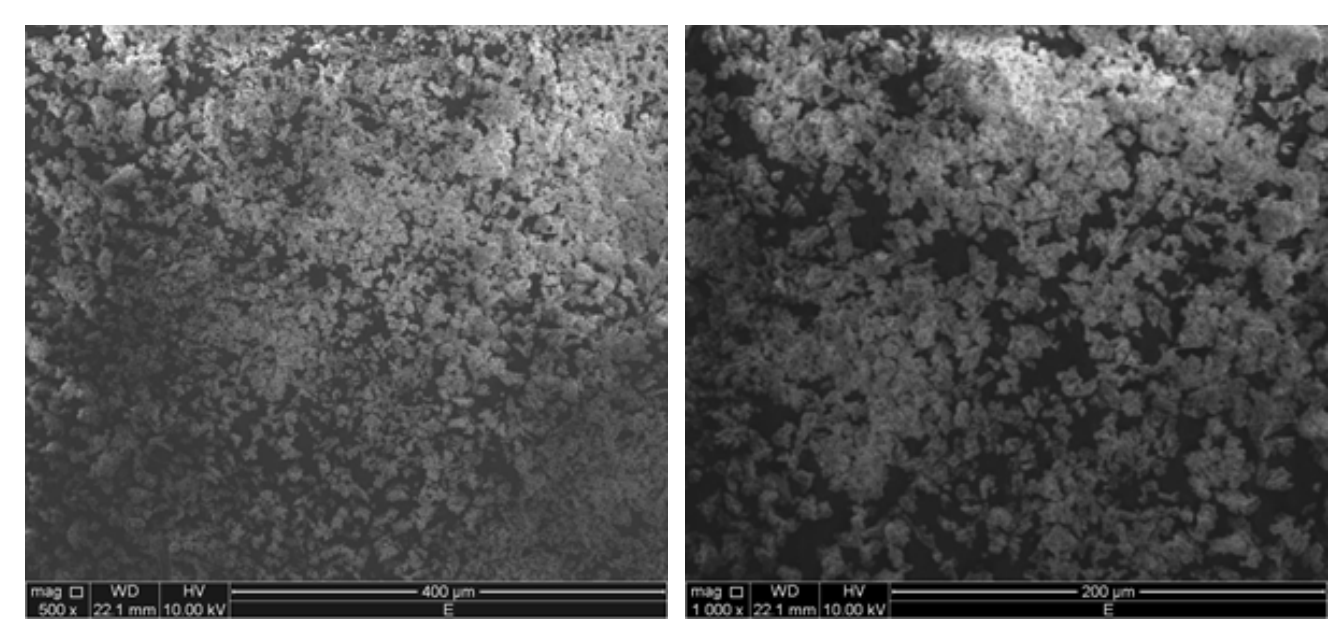

Figure 1. Scanning electron microscope images of calcined eggshells at magnification of (a) 500 and (b) 1000 
The shape of the particles was almost regular as can be seen from Figures. $1 \mathrm{a}$ and $1 \mathrm{~b}$ Similar observations have been reported by Yin et al. (2016) and Zeng et al. (2015).

The FTIR spectrum of the catalyst derived from the calcined eggshells is shown in Figure 2. Major absorption peaks were observed at 3363.97, $1612.54,1219.051033 .88$ and $833.28 \mathrm{~cm}^{-1}$. The peak at $3363.97 \mathrm{~cm}^{-1}$ corresponds to an asymmetric streching $\mathrm{OH}$ from $\mathrm{Ca}(\mathrm{OH})_{2}$ formed as a result of the fact that $\mathrm{CaO}$ readily absorbs moisture on exposture to the atmosphere. The peaks at 1612.54 and $1219.05 \mathrm{~cm}^{-1}$ are ascribed to the carbonyl functional group while that at $1033.88 \mathrm{~cm}^{-1}$ is attributed to the streching vibration of $\mathrm{Si}-\mathrm{O}$ and the peak at $833.28 \mathrm{~cm}^{-1}$ is characteristics of carbonyl functional group.

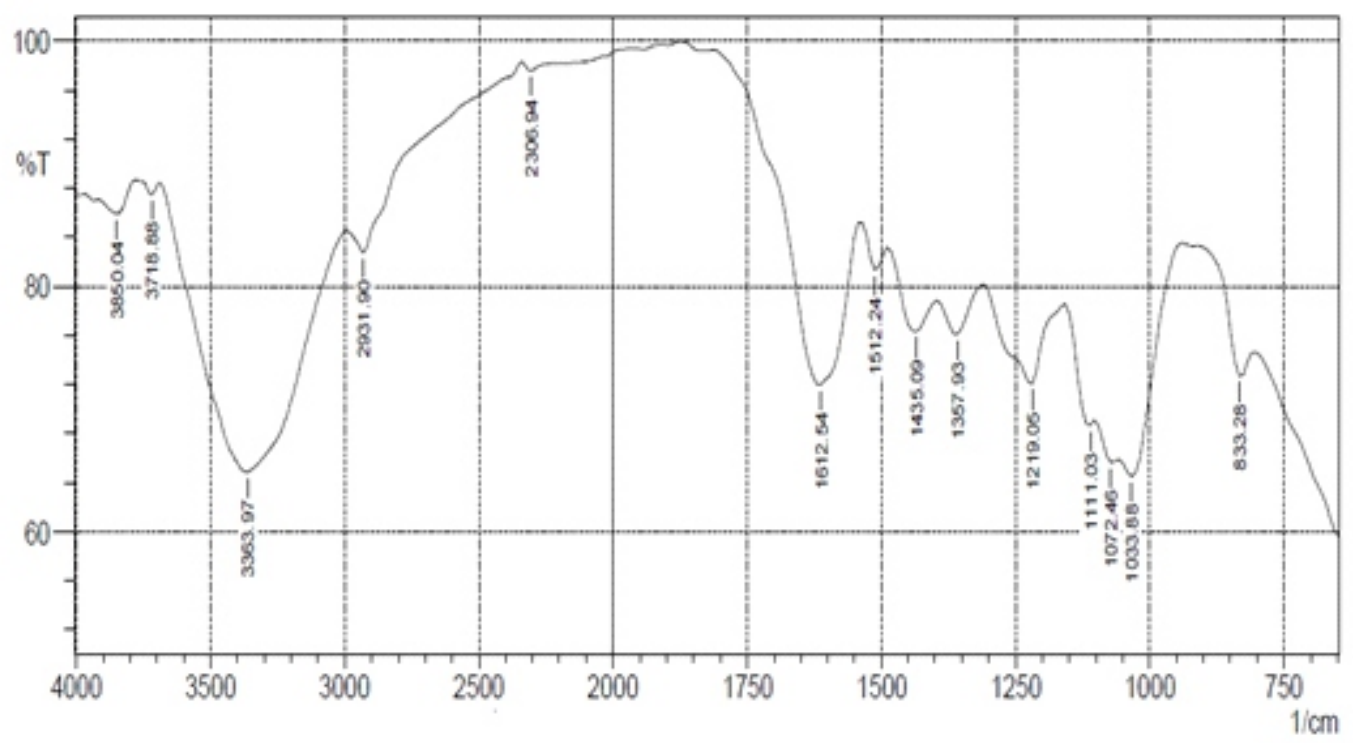

Figure 2. FTIR spectrum of the catalyst derived from calcined eggshell

Modelling and Optimization of the Transesterification Reaction

\section{Quadratic Regression Model}

Experimental results were fitted using the polynomial equation (Eq. (3)) by multiple regression analysis to obtain the quadratic regression model for the transesterification of PKO based on the coded values shown in Eq. (5).

$\mathrm{Y}=73.08-10.05 X_{1}-3.83 X_{2}-0.68 X_{3}+$ $7.82 X_{4}+8.09 X_{1} X_{2}+7.24 X_{1} X_{3}+10.17 X_{1} X_{4}$ $-1.34 X_{2} X_{3}-2.18 X_{2} X_{4}-5.72 X_{3} X_{4}+0.26 X_{1}^{2}$ $+1.27 X_{2}^{2}-15.13 X_{3}^{2}-0.32 X_{4}^{2}$

Where $\mathrm{Y}$ is the biodiesel yield, $X_{1}$ is the methanol to oil molar ratio, $X_{2}$ is the catalyst concentration, $X_{3}$ is the reaction temperature and $X_{4}$ the reaction time.

The statistical significance and fitness of the developed model as well as the significance of the individual and interacting terms were analysed using ANOVA. The ANOVA results are presented in table 5 . The model $\mathrm{F}$ - value of 199.19 and $\mathrm{p}$ - value less than 0.0001 was an indication of the high significance of the model. The significance of each model terms was also checked using the F - value and $\mathrm{p}$ - value. Results indicated that most significant term in the model was the methanol to oil molar ratio $\left(\mathrm{X}_{1}\right)$ with an $\mathrm{F}$ value of 447.18 , followed by the reaction time $\left(\mathrm{X}_{4}\right)$ with $\mathrm{F}$ - value of 270.73 . Temperature $\left(\mathrm{X}_{3}\right)$ was not a significant term in the model based on the $\mathrm{p}$ - value of 0.1733 . For a term to be significant, $\mathrm{p}-$ value must be less than 0.05 . All the interacting terms were significant with $\left(\mathrm{X}_{1} \mathrm{X}_{4}\right)$ being the most significant. The lack of fit was also determined for the quadratic model. The lack of fit $F$ value of 1.13 and $\mathrm{p}$ - value of 0.4743 was not significant, an indication that the model sufficiently describes the relationship between the transesterification variables and the biodiesel yield. The coefficient of variation (CV) was also used to check the 
adequacy of the model. According to Daniel (1991), the CV should not be more than $10 \%$. The CV was $3.76 \%$, which further confirms the model adequacy. The $\mathrm{R}^{2}$ value was also used to test the suitability of the model. The $\mathrm{R}^{2}$ value of 0.9946 which is close to one indicates an excellent agreement between experimental and predicted biodiesel yield. In order words, only $0.54 \%$ of the variations in the biodiesel yield could not be explained by the quadratic model. The predicted $R^{2}$ value of 0.9763 was in reasonable agreement with the adjusted $\mathrm{R}^{2}$ value of 0.9897 , i.e. the difference is less than 0.2 .

Table 5. ANOVA results for the second-order quadratic model

\begin{tabular}{lllllll}
\hline Source & $\begin{array}{l}\text { Sum of } \\
\text { squares }\end{array}$ & $\mathrm{df}$ & $\begin{array}{l}\text { Mean } \\
\text { Square }\end{array}$ & F value & $\begin{array}{l}\text { p-value } \\
\text { Prob. }>\mathrm{F}\end{array}$ & \\
\hline Model & 15111.44 & 14 & 1079.39 & 199.19 & $<0.0001$ & significant \\
$\mathrm{X}_{1}$ & 2423.26 & 1 & 2423.26 & 447.18 & $<0.0001$ & \\
$\mathrm{X}_{2}$ & 352.70 & 1 & 352.70 & 65.09 & $<0.0001$ & \\
$\mathrm{X}_{3}$ & 11.08 & 1 & 11.08 & 2.04 & 0.1733 & \\
$\mathrm{X}_{3}$ & 1467.09 & 1 & 1467.09 & 270.73 & $<0.0001$ & \\
$\mathrm{X}_{1} \mathrm{X}_{2}$ & 1048.40 & 1 & 1048.40 & 193.47 & $<0.0001$ & \\
$\mathrm{X}_{1} \mathrm{X}_{3}$ & 838.51 & 1 & 838.51 & 154.73 & $<0.0001$ & \\
$\mathrm{X}_{1} \mathrm{X}_{4}$ & 1656.41 & 1 & 1656.41 & 305.67 & $<0.0001$ & \\
$\mathrm{X}_{2} \mathrm{X}_{3}$ & 28.63 & 1 & 28.63 & 5.28 & 0.0363 & \\
$\mathrm{X}_{2} \mathrm{X}_{4}$ & 76.02 & 1 & 76.02 & 14.03 & 0.0019 & \\
$\mathrm{X}_{3} \mathrm{X}_{4}$ & 443.57 & 1 & 443.57 & 81.85 & $<0.0001$ & \\
$\mathrm{X}_{1}{ }^{2}$ & 1.79 & 1 & 1.79 & 0.33 & 0.5740 & \\
$\mathrm{X}_{2}{ }^{2}$ & 44.53 & 1 & 44.53 & 8.22 & 0.0118 & \\
$\mathrm{X}_{3}{ }^{2}$ & 6281.80 & 1 & 6281.80 & 1159.21 & $<0.0001$ & \\
$\mathrm{X}_{4}{ }^{2}$ & 2.79 & 1 & 2.79 & 0.51 & 0.4843 & \\
Residual & 81.29 & 15 & 5.42 & & & \\
Lack of fit & 56.36 & 10 & 5.64 & 1.13 & 0.4743 & not significant \\
Pure error & 24.92 & 5 & 4.98 & & & \\
Cor Total & 15192.72 & 29 & & & \\
C.V. $=3.767 \%$ & $\mathrm{R}^{2}=0.9946$ & Adj. $\mathrm{R}^{2}=0.9897$ & Pred. $\mathrm{R}^{2}=0.9763$ & \\
Adeq. Precision $=50.430$ & & & & & \\
\hline
\end{tabular}

A plot of the predicted biodiesel yield versus the experiment biodiesel yield is shown in Figure 3. The random scattering of data points around the diagonal line is futher evident of the suitability of the developed model. "Adeq Precision" which measures the signal to noise ratio had a value of 50.430 which is greater than 4 . It thus indicates an adequate signal and the model can be used to navigate the design space. 


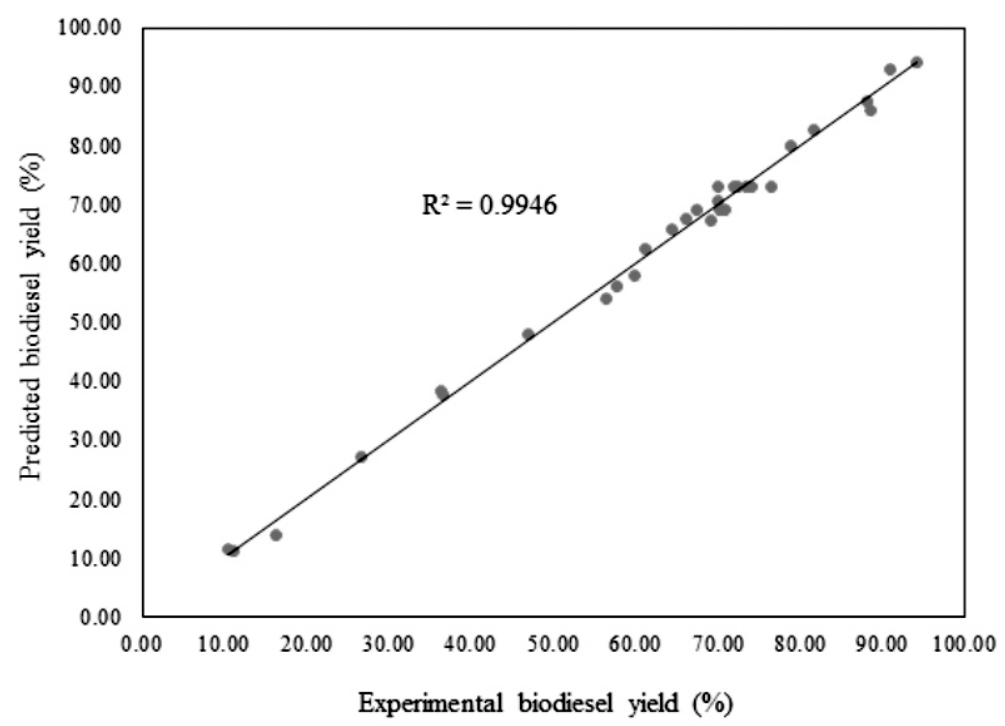

Figure 3. Predicted and experimental biodiesel yield

\section{Interactive Effect of Variables on the Biodiesel Yield}

The response surface plots shown in figure 4 is used to described the interactive effect of two variables on the biodiesel yield, while the other two variables are kept constant at their central point. The response surface plot of the biodiesel yield as a function of methanol to oil ratio and catalyst concentration at a temperature of $52.5^{\circ} \mathrm{C}$ and time of $135 \mathrm{~min}$ is shown in figure 4a. From the figure, it is observed that an increase in methanol to oil ratio from 9:1 to 15:1 at a catalyst concentration of $3 \mathrm{wt} \%$ reduces the biodiesel from 92.04 to $60.50 \%$. However, there was a slight decrease in biodiesel yield at methanol to oil ratio of 9:1, when the catalyst concentration was increased. The response surface plot of the interactive effect of methanol to oil ratio and temperature at $5 \mathrm{wt} . \%$ catalyst concentration and reaction time of $135 \mathrm{~min}$ on the biodiesel yield is shown in figure $4 \mathrm{~b}$. Increasing the reaction temperature increases the biodiesel yield. However, beyond reaction temperature of $53.5^{\circ} \mathrm{C}$, there is a decrease in the biodiesel yield. The interacting effect of methanol to oil ratio and time at a catalyst concentration of 5 wt. $\%$ and a reaction temperature of $52.5^{\circ} \mathrm{C}$ is shown in figure $4 c$. Increasing methanol to oil ratio at a constant time of 82.5 min reduces the biodiesel yield. On the other hand, there is an increase in the biodiesel yield with increase in the reaction time from 82.5 min to 187.5 min at a constant methanol oil ratio of 9:1. Figure $4 d$ shows the response surface plots which describe the interactive effect of catalyst concentration and temperature on the biodiesel yield. Increasing catalyst concentration at fixed reaction temperature do not have significant effect on the biodiesel yield as seen in the figure. It was also observed that maximum biodiesel yield is obtained at about $53.75{ }^{\circ} \mathrm{C}$. The interactive effect of catalyst concentration and time at methanol to oil ratio of 12 and reaction temperature of $52.5^{\circ} \mathrm{C}$ is shown in figure 4e. A slight reduction in biodiesel yield was observed at increasing catalyst concentration while keeping the reaction time constant at 82.5 min. Increasing both catalyst concentration and time increases the biodiesel yield from $68.03 \%$ to $75.81 \%$.

Figure $4 \mathrm{f}$ shows the response plot of the interactive effect of reaction temperature and time on the biodiesel yield. From the figure, at a fixed reaction temperature, there is an increase in biodiesel yield when the reaction time was increased. 

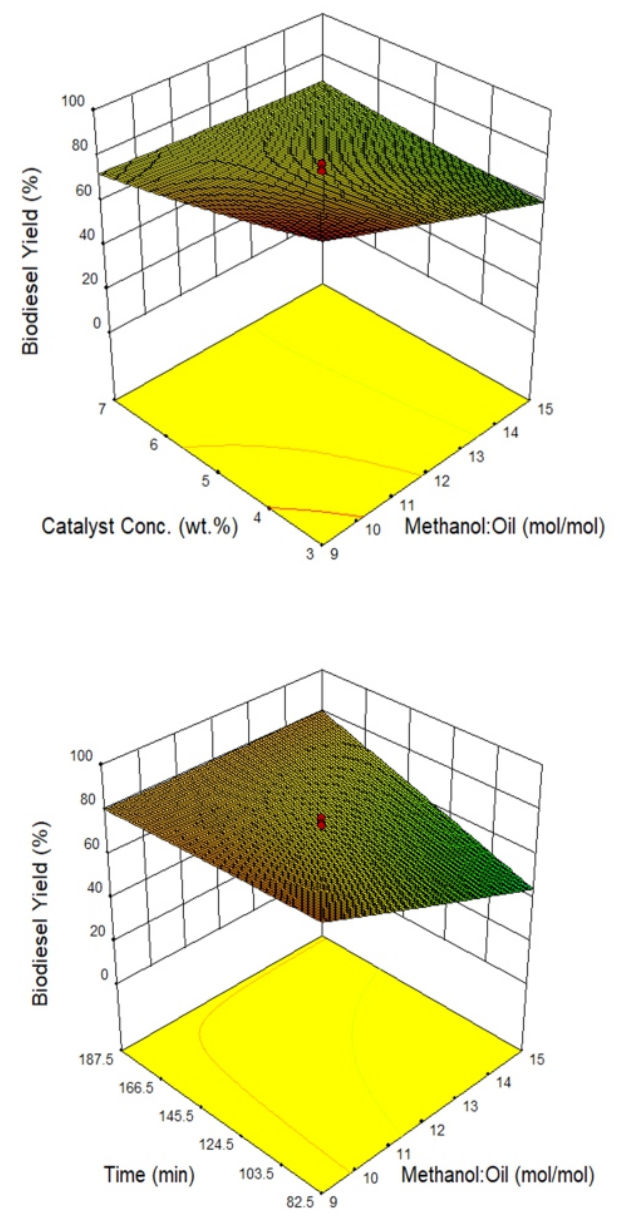

e

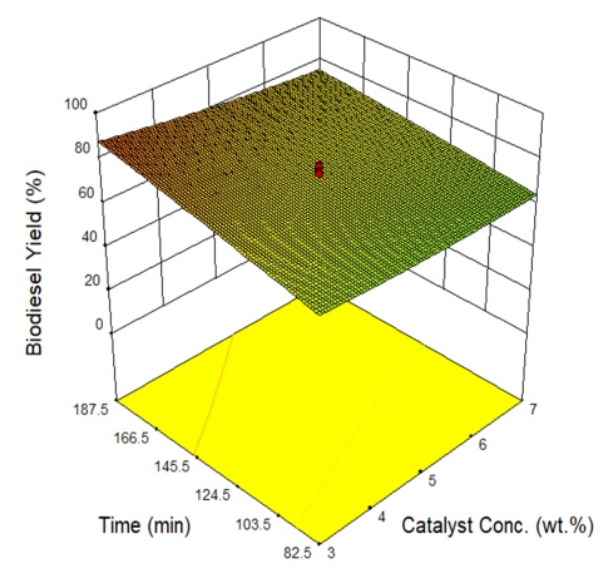

$\mathrm{b}$

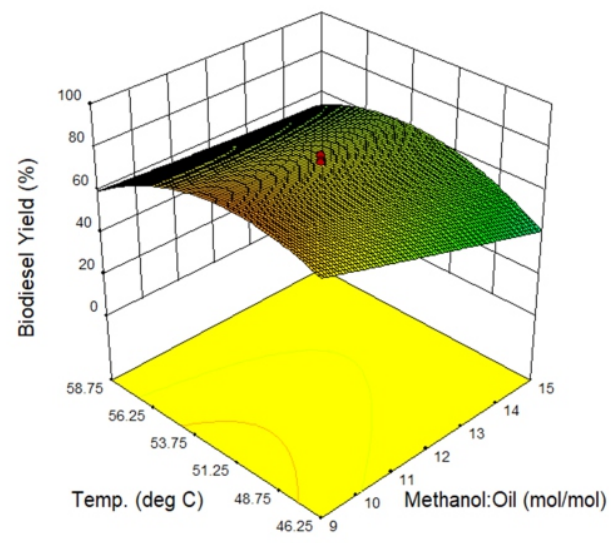

d

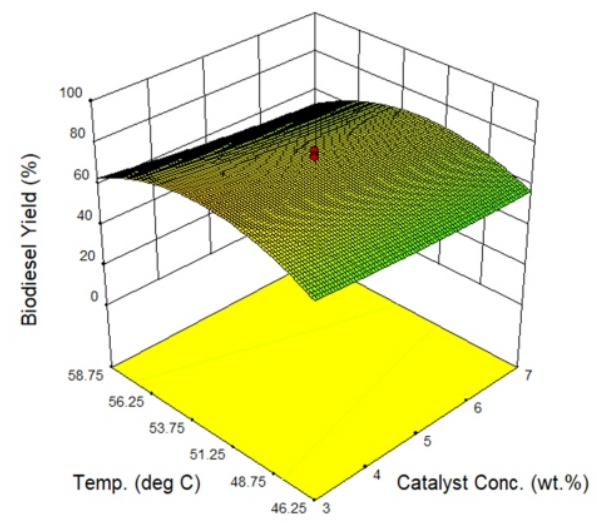

$\mathrm{f}$

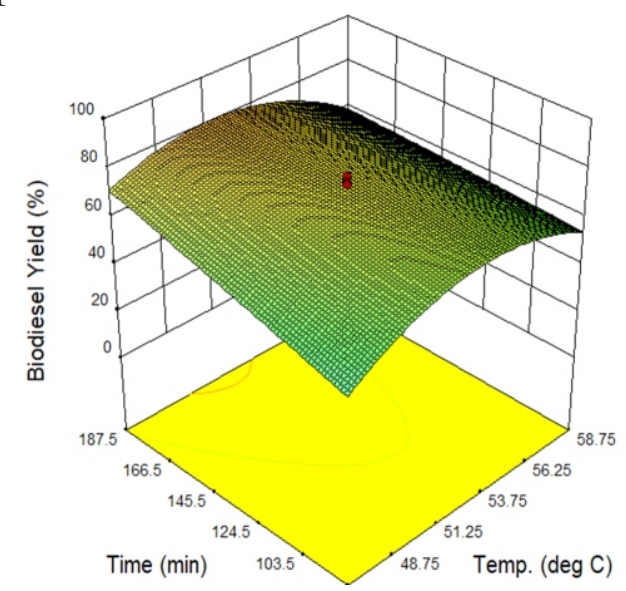

Figure 4. Response surface plots of biodiesel yield between (a) methanol:oil ratio and catalyst concentration (b) methanol:oil ratio and temperature (c) methanol to oil ratio and time (d) catalyst concentration and temperature (e) catalyst concentration and time (f) temperature and time 
Optimization of Biodiesel Yield and Model Verification

The optimum conditions for achieving maximum biodiesel yield was calculated using RSM numerical optimization. The solutions to the numerical optimization were methanol to oil molar ratio of 9:02:1, catalyst concentration of 3.106 wt.\%, temperature of $51.39{ }^{\circ} \mathrm{C}$ and a reaction time of $135.94 \mathrm{~min}$. Verification of the quadratic model was done by carrying out transesterification under the optimal conditions. The mean experimental yield was $94.63 \%$, slightly different from the predicted value of $96.395 \%$. The experimental biodiesel yield was compared with yield obtained by other researchers who used eggshell as heterogeneous catalyst in transesterification reaction as shown in table 6 .

Table 6. Comparison of biodiesel yield using different oils and eggshells as catalyst

\begin{tabular}{llclcccc}
\hline $\begin{array}{l}\text { Eggshell } \\
\text { source }\end{array}$ & Feedstock & M:O & $\begin{array}{l}\text { Catalyst } \\
\text { conc. }(\mathrm{wt} . \%)\end{array}$ & $\begin{array}{c}\text { Temp. } \\
\left({ }^{\circ} \mathrm{C}\right)\end{array}$ & $\begin{array}{c}\text { Time } \\
(\mathrm{min})\end{array}$ & $\begin{array}{l}\text { Yield } \\
(\%)\end{array}$ & Reference \\
\hline Duck & Soybean oil & $10: 1$ & 10 & 60 & 80 & 94.6 & Yin et al. $(2016)$ \\
Ostrich & used cooking oil & $12: 1$ & 1.5 & 65 & 120 & 96 & Tan et al. $(2015)$ \\
Chicken & used cooking oil & $12: 1$ & 1.5 & 65 & 120 & 96 & Tan et al. $(2015)$ \\
Hen & Soybean oil & $12: 1$ & 2 & 65 & 120 & $>95$ & Zeng et al. $(2015)$ \\
Duck & Palm oil & $9: 1$ & 20 & 65 & 240 & 92 & Buasri et al. $(2013)$ \\
Hen & Palm oil & $9: 1$ & 20 & 65 & 240 & 94 & Buasri et al. $(2013)$ \\
Hen & PKO & $9.02: 1$ & 3.106 & 51.39 & 135.94 & 94.63 & This Study \\
\hline
\end{tabular}

Methanol: Oil molar ratio (M: O)

Physicochemical Properties of PKO Biodiesel

analysed and compared with the ASTM D6751 biodiesel standard shown in table 7 . It can be seen The physicochemical properties of the biodiesel produced under optimal reaction conditions were that the major fuel properties such as density and flash point are within the biodiesel standard.

Table 7. Physico-chemical properties of PKO biodiesel

\begin{tabular}{llllc}
\hline Property & Unit & Value & Test Method & $\begin{array}{c}\text { Biodiesel Standard } \\
\text { ASTM D 6751 }\end{array}$ \\
\hline Viscosity at $25{ }^{\circ} \mathrm{C}$ & $\mathrm{mm}^{2} / \mathrm{s}$ & 4.64 & $\mathrm{D} 445$ & $1.9-6.0$ \\
Density & $\mathrm{kg} / \mathrm{m}^{3}$ & 884 & $\mathrm{D} 4052$ & $0.860-0.900$ \\
Acid value & $\mathrm{mg} \mathrm{KOH} / \mathrm{g}$ & 0.62 & $\mathrm{D} 664$ & $<0.80$ \\
Flash point & ${ }^{\circ} \mathrm{C}$ & 162 & $\mathrm{D} 93$ & $130 \mathrm{~min}$ \\
Cloud point & ${ }^{\circ} \mathrm{C}$ & 8 & $\mathrm{D} 2500$ & - \\
Iodine value & $\mathrm{gI}_{2} / 100 \mathrm{~g}$ & 72.83 & $\mathrm{D} 66411$ & $<0.05$ \\
Moisture content & $(\%)$ & 0.02 & - & \\
\hline
\end{tabular}

\section{CONCLUSION}

This study has focussed on modelling and optimizing the process parameters on the production of biodiesel from palm kernel oil using heterogeneous catalyst derived from chicken eggshell wastes. The eggshells were calcined at $900{ }^{\circ} \mathrm{C}$ for $5 \mathrm{~h}$. Calcium oxide content of the calcined eggshell was found to $98.16 \%$. The optimization of the process parameters was done using response surface methodology (RSM) based on the central composite design. The parameters optimized in the production process are methanol to oil molar ratio, catalyst concentration, temperature and time. A second order quadratic model with $R^{2}=0.9946$ was developed to predict the biodiesel yield. The predicted maximum biodiesel yield was $96.395 \%$ under the following conditions (methanol to oil ratio of 9.02:1, catalyst 
concentration of 3.106 wt. $\%$, temperature of $51.39{ }^{\circ} \mathrm{C}$ and a time of $135.94 \mathrm{~min}$. The experimental value obtained under these same conditions was $94.63 \%$. The quality of the biodiesel produced under these optimum conditions is in the range of the ASTM standard for biodiesel.

\section{REFERENCES}

Akhabue, C. E. and Okwundu S. O. (2017). Monitoring the transesterification reaction of castor oil and methanol by ultraviolet visible spectroscopy. Biofuels. Available in http://doi.org/10.1080/ 17597269.2017.1338128.

Birla, A., Singh, B., Upadhyay, S. N. and Sharma, Y. C. (2012) Kinetics studies of synthesis of biodiesel from waste frying oil using a heterogeneous catalyst derived from snail shell. Bioresource Technology 106: 95-100.

Buasri, A., Chaiyut, N., Vorrada L., Wongweang, C., Khamsrisuk, S. (2013) Application of eggshell wastes as a heterogeneous catalyst for biodiesel production. Sustainable Energy 1(2): 7-13.

Daniel, W. W. (1991) Biostatistics: A foundation in the health sciences $\left(5^{\text {th }}\right.$ edition). New York: Wiley. P. 12.

Dharma, S., Masjuki, H. H., Ong, H. C., Sibayang, A. H., Silitonga, A. S., Kusumo, F., Mahlia, T. M. I. (2016). Optimization of biodiesel production process for mixed Jatropha curcas-ceiba pentandra biodiesel using response surface methodology. Energy and Conversion Management 115:178-190.

Eswararao, Y., Niju, S., Begum, K. M. M. S., Anantharaman, N. and Raj, S. M. (2016) Transesterification of jatropha oil using mixture of natural shells as solid catalyst. Biofuels. Available in http://dx.doi. org/10.1080/17597269.2015.1138036

Gupta, J. and Agarwal, M. (2016) Preparation and characterization of highly active solid based catalyst from snail shell for biodiesel production. Biofuels. Available in http:// dx.doi.org/10.1080/17597269.2016.1200 862

Hess, M. A., Hass, M. J., and Foglia, T. A., (2007). Attempts to reduce $\mathrm{NO}_{\mathrm{x}}$ exhaust emission by using reformulated biodiesel. Fuel Processing Technology 88:693-699.
Hideki, F., Akihiko, K., Hideo, N., (2001). Biodiesel fuel production by transesterification of oils. Journal of Bioscience and Bioengineering 92 (5), pp. 405 416.

Kostic, M. D., Bazargan, A., Stamenkovic, O. S., Veljkovic, V. B. and McKay, G. (2016) Optimization and kinetics of sunflower oil methanolysis catalysed by calcium oxide-based catalyst derived from palm kernel shell biochar. Fuel163:304-313.

Laca, A., Laca, A., Diaz, M. (2017) Eggshell wastes as a catalyst: A review. Journal of EnvironmentalManagement 107:351 - 359.

Monyem, A. and Van Gerpen, J., H., (2001). The effect of biodiesel oxidation on engine performance and emissions. Biomass and Bioenergy 20:317-325.

Rezaei, R., Mohadesi, M. and Moradi, G. R. (2013) Optimization of biodiesel production using waste mussel shell catalyst. Fuel 109: $534-541$.

Shahla, S., Ngoh, G. C., Yusoff, R. (2012). The evaluation of various kinetic models for base-catalyzed ethanolysis of palm oil. Bioresource Technology 104:1-5

Tan, Y. H., Abdullah, M. O., Nolasco - Hipolito, C. and Taufiq - Yap, Y. H. (2015) Waste ostrich - and chicken - eggshells as heterogeneous base catalyst for biodiesel production from used cooking oil: catalyst characterization and biodiesel yield performance. Applied Energy 160:58 - 70 .

Tariq, M., Ali, S., Khalid, N. (2012) Activity of homogeneous and heterogeneous catalysts, spectroscopic and chromatographic characterization of biodiesel: A review. Renewable and Sustainable Energy Reviews 16: 6303-6316.

Viriya -empikul, N., Krasae, P., Nualpaeng, W., Yoosuk, B. and Faungnawakij, K. (2012) Biodiesel production over Ca-based solid catalysts derived from industrial wastes. Fuel 92: 239-244.

Ye, W., Gao, Y., Ding, H., Liu, M., Liu, S., Han, X., Qi, J. (2016) Kinetics of transesterification of palm oil under conventional heating and microwave irradiation using heterogeneous catalyst. Fuel 180: $574-$ 579.

Yin, X., Duan, X., You, Q., Dai, C., Tan, Z., Zhu, 
X. (2016) Biodiesel production from soybean oil deodorizer distillate using calcined duck eggshell as catalyst. Energy Conversion Management 112: 199-207.

Zeng, D., Zhang, Q., Chen, S., Liu, Chen, Y., Tian,
Y. (2015) Preparation and characterization of a strong base from waste eggshell for biodiesel production. Journal of Environmental Chemical Engineering 3:560 564. 